\title{
HEART BLOCK AND THE SIMULATION OF BUNDLE BLOCK IN DIPHTHERIA
}

\author{
BY \\ HAROLD COOKSON
}

Received January 4, 1945

Cardiographic studies in diphtheria show that a wide variety of arrhythmias and abnormalities of pattern occur. Among these heart block is familiar, not so much because it is common, but because in its more severe forms it indicates a grave prognosis. Burkhardt, Eggleston, and Smith (1938) recorded 11 cases of A-V dissociation, all fatal; some presented a terminal ventricular tachycardia. They noted a high idio-ventricular rate of $80-90$ so that block was not suspected before the cardiogram was taken.

Alstead (1932) found the P-R interval to exceed $0.2 \mathrm{sec}$. only once in 100 cases, although in 10 others this interval increased during the disease: two of his cases said to show complete block died; but the tracing of one of these is not convincing. Stecher (1928-29) studied 19 cases of complete block in diphtheria; all died. He publishes tracings of 11 cases; four of these show complete block, but of the remainder four show ventricular tachycardia and one normal rhythm with bigeminy. Nathanson (1928) described T wave changes in 7 cases, but noted no conduction changes; his Case 3 does, however, show a wide QRS. Friedemann (1932) found the ventricular rate high in complete block, but did not note so high a mortality as most other authors, in this condition. Begg (1937) had a mortality of 66 per cent in both bundle branch block and complete block. (One of his records said to show complete block, where the auricular rate is 100 and the ventricular 135 , should perhaps be regarded as ventricular tachycardia.) Harries and Mitman (1941) state that partial block is rare, that left bundle block is commoner than right, and regard A-V block as a serious sign. On the other hand Neubauer (1942) found partial block in 17 per cent of cases (but his Fig. 10 described as showing 3: 1 block seems to show complete block) and complete block in 5 per cent. He also records auricular fibrillation associated with complete block. However, his Fig. 17 suggests complete block with normal auricular mechanism, not fibrillation; nor is auricular fibrillation evident as claimed in Fig. 14.

\section{Present Investigation}

Eighty-three cases of diphtheria were investigated clinically and serial cardiograms taken at intervals throughout the illness. About 300 cardiograms were taken in all, 2 or 3 in mild cases, more in the severe ones. In 63 of the patients the cardiogram was abnormal, that is in 76 per cent. Ten of these showed some defect of conduction; the others inversion of $\mathrm{T}$ in one or more leads; in less severe cases $\mathrm{T}$ was usually inverted in lead III only; in severe cases the inversion was seen in more than one lead, sometimes in all four. Displacement of the S-T segment was frequent, and nearly always downwards. Other abnormalities commonly seen were axis shift, slurring and slight widening of QRS, and bizarre $P$ waves. Conduction changes were relatively uncommon; there was increase in the auriculo-ventricular conduction time in four, but in only one of these did it exceed $0.2 \mathrm{sec}$. In two of these there were also changes in the $T$ waves. Bundle branch block with increase in $P-R$ was recorded in three cases, and complete block in one: all these four patients died. Three other patients without block died, one during ventricular tachycardia, one from nervous lesions when his cardiogram had returned to normal, and one showing $T$ changes and low voltage. The 
mortality for the whole series was thus 8.4 per cent. There was no fatality over the age of 12 , and none in an immunized subject.

Only ten cases are reported here, but they have been followed closely throughout their course in hospital, by the same observer, both clinically and cardiographically, and in all fatal cases necropsies were carried out and histological studies made.

\section{CASE REPORTS}

\section{Increase in $P-R$ Interval}

Case 1. J. R., age 7. Antitoxin on 8th day; pharyngeal and nasal diphtheria. 30th day, vomiting. 53rd day, palatal palsy. 83rd day, apparently quite well; EC. (electrocardiogram), N.R., rate 120; P-R, 0.18 sec.; T III just negative. 99th day, EC., N.R., rate 110; P-R, 0.15 sec.; T III flat. 111th day, EC., N.R., rate 90; P-R, 0.15 sec.; T III positive.

Case 2. M. D., age 18. Antitoxin on 7th day; pharyngeal diphtheria. 7th day, EC., N.R., rate 110; P-R, 0.16 sec. 13th day, EC., rate 75; $P$ broad and bifid; $P-R, 0.18$ sec. 25th day, EC., N.R., rate 115; P-R, 0.2 sec. 32nd day, EC., N.R., rate 85; P broad and bifid; P-R, 0.18 sec. No complications in nervous system, nor clinical signs or symptoms of myocardial injury throughout.

Case 3. Mrs. G., age 24. Antitoxin on 6th day; pharyngeal diphtheria. 7th day, EC., N.R., rate 125; $P$ broad and notched; $P-R, 0.2$ sec.; right axis deviation; B.P. 125/80. 60th day, EC., N.R., rate $65 ; \mathrm{P}-\mathrm{R}, 0.15$; rate 100 with deep breathing; $\mathrm{P}-\mathrm{R}$ increasing to maximum of $0.2 \mathrm{sec}$. No symptoms.

Case 4. J. G., age 8. Antitoxin on 6th day, immunized 18 months before; nasopharyngeal diphtheria. 8th day, EC. (Fig. 1A), N.R., rate 105; P-R, $0.15 \mathrm{sec}$; slight depression of S-T in leads II and III. 22nd day; general condition good, no complications in nervous system; apex beat in mid-clavicular line fourth interspace; sounds normal at apex; wavy systolic pulsation to left of sternum in second and third interspaces; systolic murmur and second sound duplicated at pulmonary area; B.P. 95/55; liver edge three-quarters of an inch below right costal margin; EC. (Fig. 1B), N.R., rate $100 ; \mathbf{P}-\mathbf{R}, 0.2$ sec., S-T depression in leads I, II, and IVR; elevation in III; T diphasic in II and IVR, negative in III. 32nd day, EC., N.R., rate 85; P-R, $0.2 \mathrm{sec}$.; T now positive in leads II

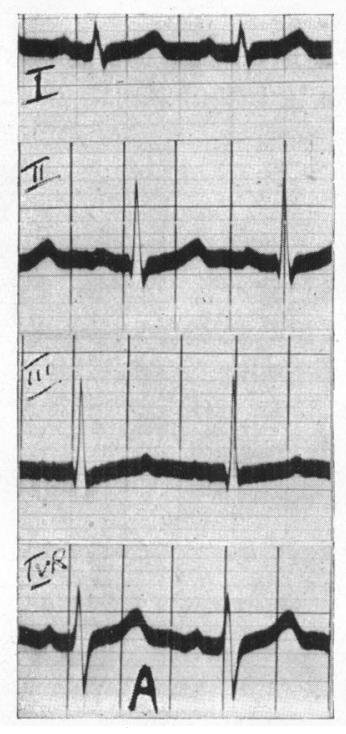

FIG. 1.-Case

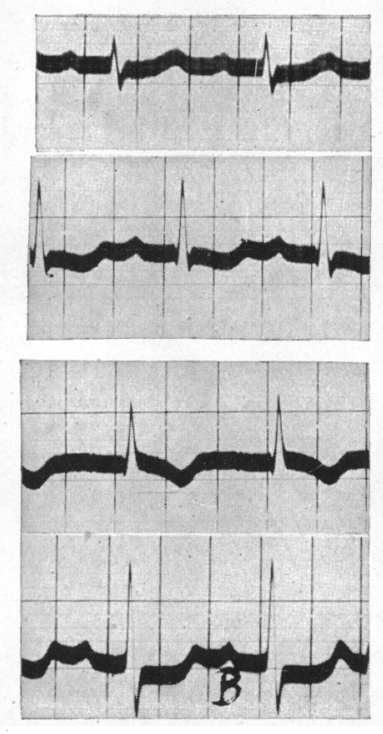

See text.

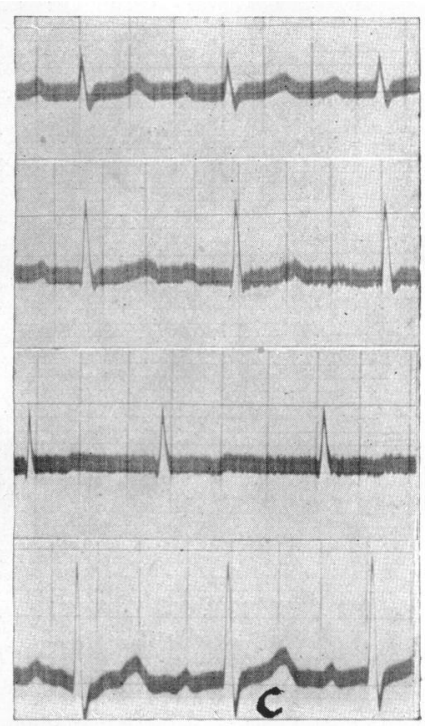

(B) 22nd day. (C) 5 months later.

and IVR and less negative in III; cardiac signs as before except that a faint blowing diastolic murmur was audible in the third interspace near the sternum. Discharged from hospital on the 80th day. On re-examination 3 months later, child seemed quite well; apex beat just outside mid-clavicular line; wavy precordial systolic pulsation; short rough diastolic murmur at apex in lying position; faint blowing diastolic murmur in third left interspace; B.P. 110/60; on radioscopy, pulmonary arc prominent, left ventricular contour slightly prominent, and left auricle not enlarged; EC., N.R., rate $90 ; \mathbf{P}-\mathbf{R}, 0.21 \mathrm{sec}$; T III negative. The signs indicated that mitral stenosis and aortic incompetence were present and that rheumatic carditis had occurred some time before the attack of diphtheria. Examination 2 months later ( 5 months after discharge from hospital) showed no change in 
physical or radioscopic signs; cardiogram (Fig. 1C) showed the P-R interval to be still $0 \cdot 21$ sec.; $T$ inversion in lead III less and $R$ in lead IVR of greater amplitude.

\section{Prolonged $P-R$ and Bundle Branch Block}

Case 5. V. F., age 3. Antitoxin on 3rd day. Faucial diphtheria; B.P. 95/55. 7th day no clinical signs or symptoms of circulatory failure; B.P. 70/50; EC. (Fig. 2A), N.R., rate 105; P-R, $0 \cdot 18$ to 0.2 sec.; right bundle branch block (B.B.Bl.) but alternate beats in lead II show no B.B.BI. 8th day vomiting and collapse. 9th day: B.P. 60/30; apex beat visible half an inch outside midclavicular line; heart sounds normal; liver edge one inch below right costal margin; EC. (Fig. 2B), N.R., rate 65; bundle branch block; $P$ bifid or wavy; P-R, 0.3 sec. 11th day, died.
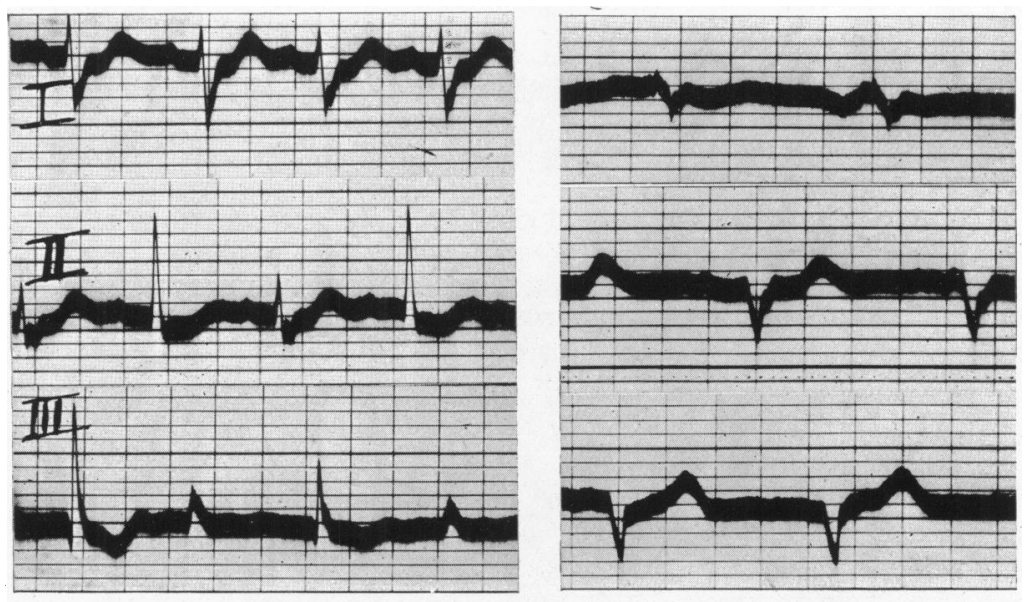

Fig. 2.-Case 5. Development of long P-R interval and bundle branch block. (A) 7th day. (B) 9th day. See text.

Necropsy. Left auricle contains adherent thrombus: on section, muscle fibres necrotic and œdematous. Right ventricle on section, degeneration of muscle; congestion and cellular infiltration. Left ventricle, on section, areas of advanced degeneration; some early fibrosis. Liver: intense venous congestion; necrosis in central part of lobules.

Case 6. A. G., age 12. Antitoxin on 2nd day (26 hours after onset). Faucial diphtheria, bullneck, heavy albuminuria. 3rd day, apex beat difficult to feel, probably in mid-clavicular line; sounds normal; B.P. 95/70; EC. (Fig. 3A), N.R., rate 120, sinus arrhythmia; S-T depression in leads II and III; QRS, 0.07 sec.; P peaked in leads II and III, P-R, 0.12 sec. 8th day, swelling of neck almost gone; able to take light solid diet; palatal palsy; apex beat within mid-clavicular line, fourth interspace; systolic retraction in third left interspace; sounds normal; B.P. 80/60; liver not felt;
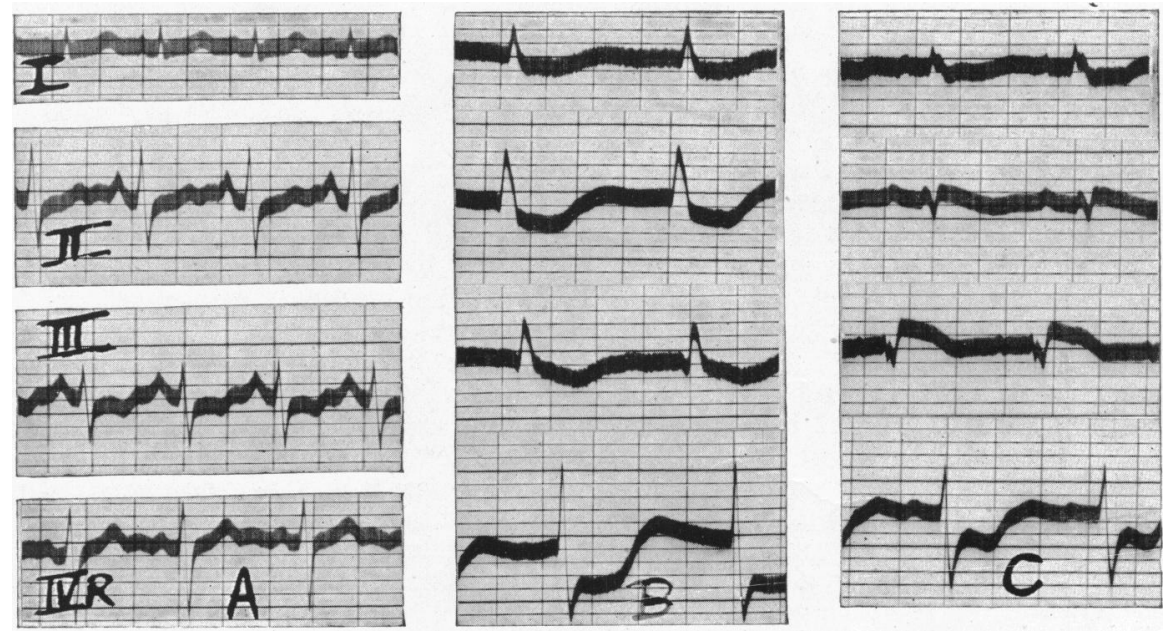

FIG. 3.-Case 6. Lengthening of P-R interval and widening of QRS complexes. (A) 3rd day. (B) 8th day.

(C) 10 th day. See text. 
knee and ankle jerks present; EC. (Fig. 3B), regular rhythm rate $80 ; \mathrm{P}$ wave not seen; QRS, $0 \cdot 1$ sec.; S-T depression in all leads. 10th day, vomiting; first sound very distant; second well heard; B.P. 70/60; jugular vein well seen, but not above level of second costal cartilage; liver not palpable; trace of albuminuria; EC (Fig. 3C), N.R., rate 90; P-R, 0.18 sec.; S-T deviation downwards in leads I and IVR, upward in II and III; QRS, $0 \cdot 1 \mathrm{sec}$. Died suddenly two hours later after incision for intravenous infusion.

Necropsy. Heart: weight, $175 \mathrm{~g}$.; left ventricle maximum thickness $1.2 \mathrm{~cm}$., minimum $0.7 \mathrm{~cm}$.; right ventricle, maximum thickness $0.5 \mathrm{~cm}$.; 15 c.c. clear yellow fluid in right pleura, 7 c.c. in left pleura. On section, myocardium showed congestion, œdema, degeneration up to stage of necrosis, and cellular infiltration mainly with plasma cells, in all chambers, most in left ventricle; areas of intense congestion and cellular infiltration in pericardium. Liver: enlarged, edge reaching to within a quarter of an inch of umbilicus; on section, venous congestion, necrosis in central and mid-portions of lobules. Kidney: venous congestion; degeneration of tubular epithelium. Lung: areas of collapse and œdema separated by areas of emphysema.

Case 7. B. E., age 3. First antitoxin on the 5th day of the disease; faucial diphtheria. 6th day: apex beat fourth interspace not outside mid-clavicular line; sounds normal and well heard; B.P. $90 / 65$; EC., N.R., rate 135, slight right axis deviation; $P$ high voltage; P-R, $0.15 \mathrm{sec}$.; T III flat; T in IVR low voltage and diphasic. 7th day: triple rhythm at apex on inspiration; B.P. 90/70; EC. (Fig. 4A) as on previous day but rate 125. 9th day: triple rhythm at apex; B.P. 95/55; liver palpable and tender; slight dyspnoea; vomited once; heavy albuminaria. EC., N.R., rate 110; left bundle branch block; P-R, 0.18 sec. (Fig. 4B). 10th day, neck swelling almost gone; vomited once; apex beat not felt; triple rhythm at apex; B.P. 90/60. EC. (Fig. 4C), N.R., rate 110; L.B.B.Bl. but QRS altered since previous tracing; occasional supra-ventricular premature beat.
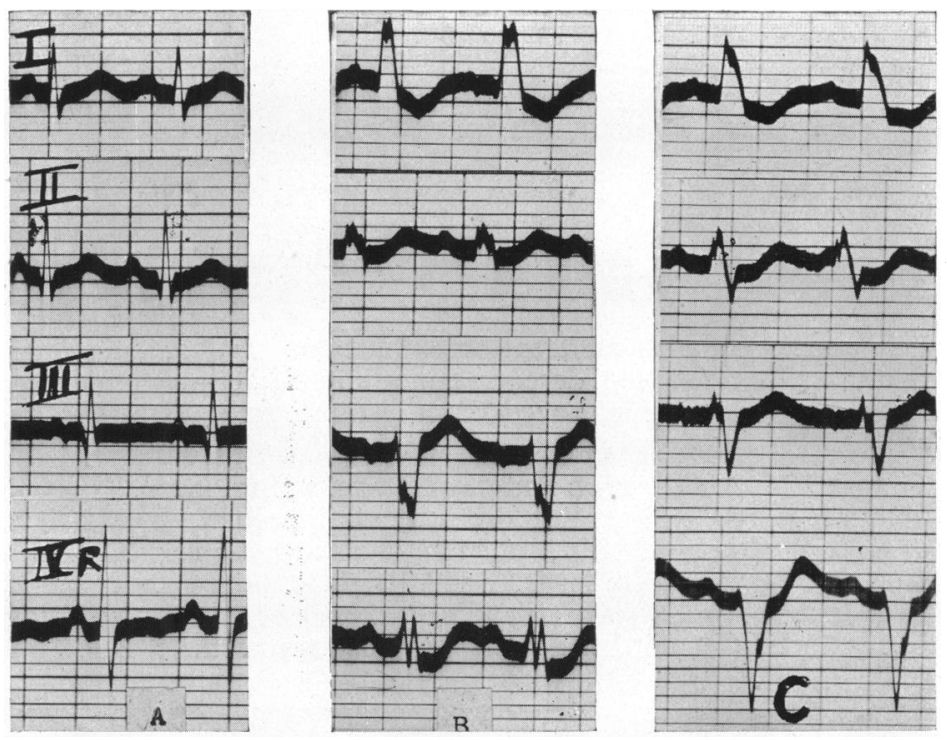

Fig. 4.-Case 7. Lengthening of P-R interval and development of bundle branch block. (A) 7th day. (B) 9 th day. (C) 10th day. See text.

11th day, vomiting, pain over liver, which is increasing in size; apex beat fifth space within midclavicular line; triple rhythm not heard; B.P. 80/45; EC., N.R., rate 95; irregularity due to sinus arrhythmia, nodal escape and interference dissociation; P-R, 0.1 to $0 \cdot 3 \mathrm{sec}$., L.B.B.Bl.: same day, 6.30 p.m., having intramuscular glucose-saline; B.P. 75/45; liver still larger; EC. similar to previous tracing but $P$ flatter, and $P-R$ up to $0.38 \mathrm{sec}$. 12th day: vomiting; nasal regurgitation; diffuse precordial pulsation; no apex beat palpable; shallow occasional sighing respiration; no signs in lungs; deep reflexes present; B.P. 65/45; EC. (Fig. 5), N.R., rate 90; sinus arrhythmia and nodal escape; bundle branch block of $S$ type and of $R$ type according to whether sinus or nodal rhythm is present; S-T depression in all leads. 13th day, vomiting, restlessness, pallor, constant sighing; apex beat not palpable, but visible in fourth and fifth interspaces and extending just outside mid-clavicular line; sounds distant; systolic murmur at apex; liver larger; B.P. 55/40, no signs in lungs. EC. (Fig. 6A), N.R., rate 105; P-R, 0.15 sec., bundle branch block of indeterminate type; 1/200 of a grain of atropine was given intramuscularly and ten minutes later the cardiogram had altered, becoming similar to the latter part of the tracing of the previous day; it shows nodal rhythm rate 92 and R.B.B.Bl. (Fig. 6B). Triple rhythm with audible third sound (Evans' type I B) was heard after the injection of atropine. 9.30 p.m., constantly sighing and crying out; radial pulse not palpable and B.P. not obtainable. EC. (Fig. 6C); nodal rhythm, rate 90; P not visible; R.B.B.Bl., QRS wider than in previous tracing; S-T depression all leads. Died two hours later. 


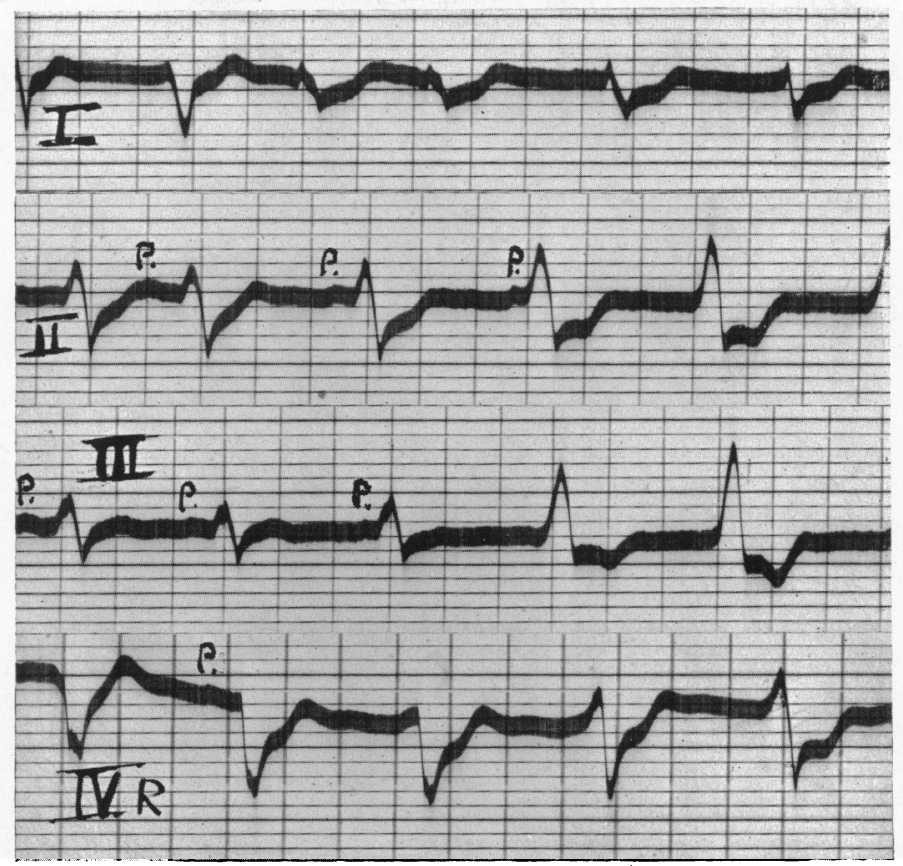

FIG. 5.-Case 7. Sinus arrhythmia and nodal escape with bundle branch block of varying type, 12th day. See text.
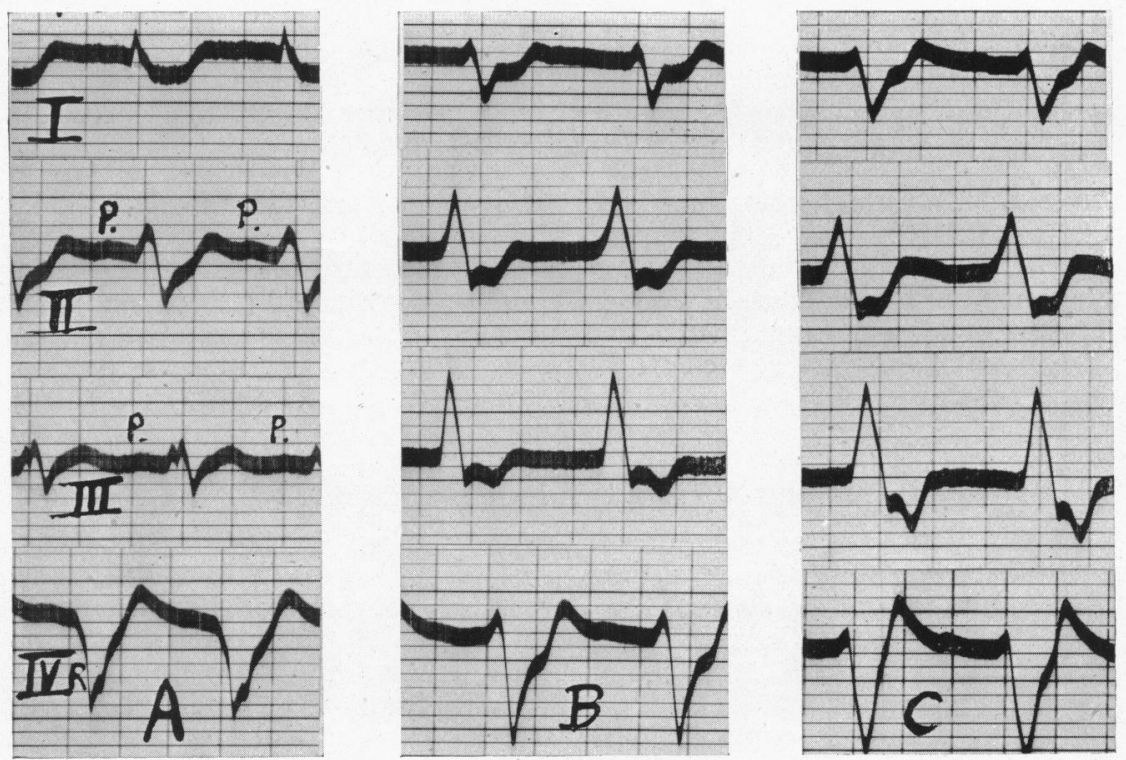

FIG. 6.-Case 7. Bundle branch block of varying type. All 13th day. See text.

Necropsy. Straw coloured effusions in both pleuræ, 450 c.c. in right, less in left; liver enlarged. Heart: weight $110 \mathrm{~g}$; ; left ventricle, maximum thickness $9 \mathrm{~mm}$., minimum $3 \mathrm{~mm}$.; right ventricle, maximum thickness $5 \mathrm{~mm}$., minimum $2 \mathrm{~mm}$.

Histology. Lungs: collapse, œdema and emphysema. Liver: marked venous congestion; advanced fatty degeneration; areas of necrosis. Heart: little normal muscle remains; advanced degeneration in all sections; areas of necrosis; œdema; a little fibrosis in left auricle and left ventricle.

\section{Complete Heart Block}

Case 8. M. L., age 8. First antitoxin on 3rd day; faucial and nasal diphtheria. 4th day: apex beat within mid-clavicular line; sounds normal; B.P. 100/50; EC. (Fig. 7A), N.R., rate 140, 
right axis deviation; P-R, $0.1 \mathrm{sec}$; slight S-T depression all leads. 6th day, vomiting and heavy albuminuria; apex beat in mid-clavicular line; sounds normal; B.P. 75/45; no liver signs; EC. (Fig. 7B) lead IVR only; rate $150 ;$ P-R, 0.15 sec., QRS, 0.12 sec. 8th day, vomiting blood; apex beat not palpable, sounds normal; petechiæ and ecchymoses in skin; EC. (Fig. 7c). Complete heart block, auricular rate 140 with sinus arrhythmia; ventricular rate 115; R.B.B.Bl.; S-T depression in all leads. 9th day, dyspnœa, vomiting; apex beat not felt; sounds normal; B.P. 60/0;
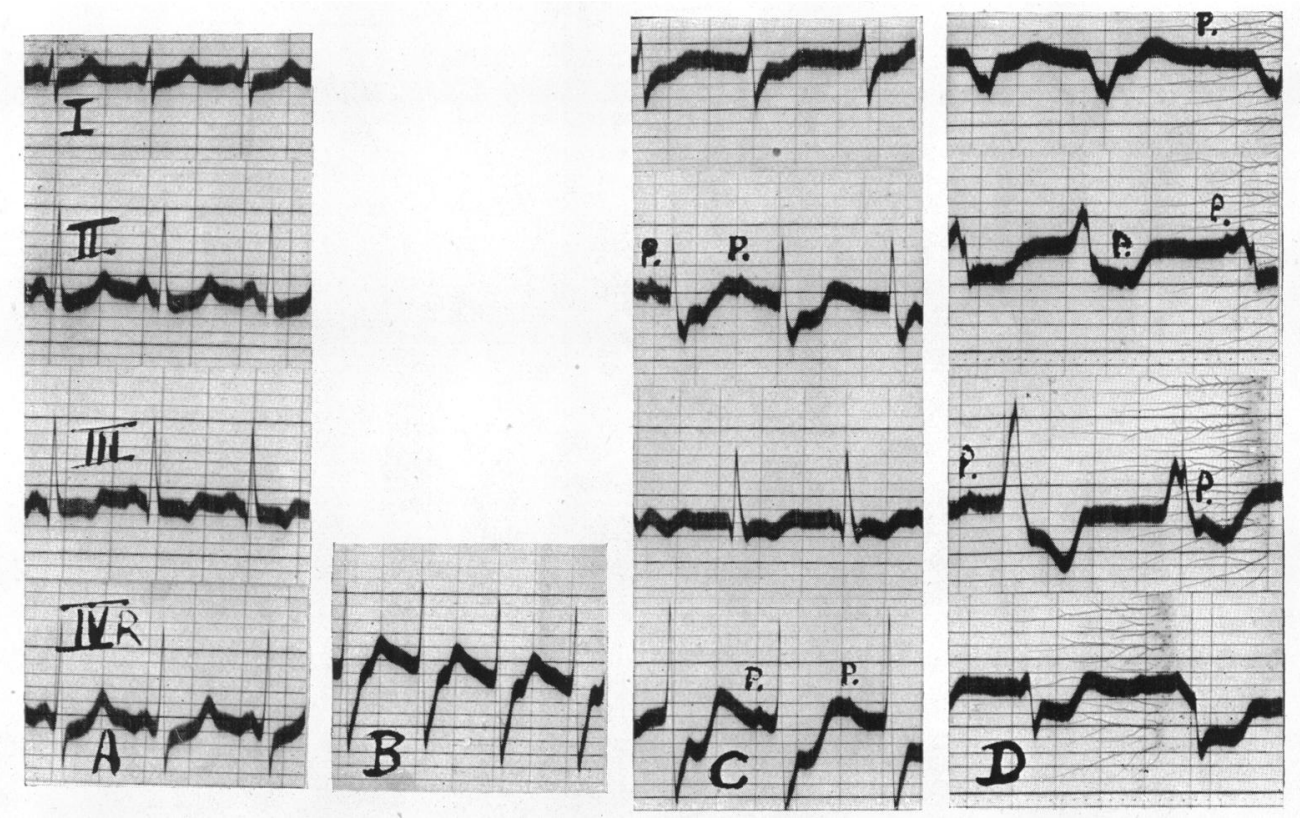

FIG. 7.-Case 8. Development of complete heart block and bundle branch block. (A) 4th day. (B) 6th day. (C) 8th day. (D) 9 th day. See text.

EC. (Fig. 7D). C.H.B. with alternate ventricular extrasystoles; auricular rate about 126, ventricular rate about 90; R.B.B.Bl. Died 3 hours later.

Necropsy. Liver: some venous congestion, necrosis in centre of lobules; fatty degeneration. Lungs: congestion and small areas of collapse. Heart: weight, $110 \mathrm{~g}$. ; left ventricle, maximum thickness $12 \mathrm{~mm}$., minimum $7 \mathrm{~mm}$., pericardial and sub-endocardial petechial hæmorrhages; some plaques of atheroma in aorta just above aortic valve cusps, largest 3 by $5 \mathrm{~mm}$.; on section, degeneration of muscle all chambers; areas of hæmorrhage into muscle; œdema slight; no cellular infiltration, no fibrosis.

\section{Cases Simulating Bundle Branch Block}

Case 9. J. P., age 8. Antitoxin given on 3rd day of disease. Diphtheria immunization 2 years previously. Mild tonsillar diphtheria; no abnormal cardiac signs; B.P. 100/50. 4th day: EC., N.R., rate 75; P-R, $0 \cdot 18$ sec., $P$ diphasic. 13th day: EC., N.R., rate 85; P-R unchanged, $P$ diphasic still, but increased in amplitude; T diphasic in leads II and III. 30th day: convalescent; no abnormal cardiac signs; EC. (Fig. 8), N.R., rate about 80; P diphasic; with sinus slowing "A-V nodal" escape beats appear with an upright QRS of $0.17 \mathrm{sec}$, depression of S-T and diphasic or positive T; in lead III a sinus rhythm only recorded; in lead II the fourth ventricular complex is preceded by a $P$ wave with a P-R interval of $0 \cdot 11 \mathrm{sec}$; this QRS is intermediate in form between the QRS of the preceding " nodal " beats and the QRS of the following sinus beats; the last " nodal" beat in lead IVR is preceded by a negative $P$ with a $P-R$ interval of $0.11 \mathrm{sec}$. 32nd day: EC., N.R., rate 88 ; no sinus arrhythmia; and no " nodal" beats, otherwise tracing unchanged. Discharged well after 37 days in hospital. On re-examination 18 months later the child was quite well; no abnormal clinical signs; radioscopy: slight prominence of left middle arc; EC., N.R., rate 70; P-R, 0.18 sec., $\mathbf{P}$ of normal shape in limb leads, but diphasic still in IVR; ventricular complex physiological.

Case 10. C. T., age 10. Antitoxin on 4th day of illness; not immunized. Naso-pharyngeal diphtheria; severe toxæmia, bull-neck. 9th day: apex beat not palpable, sounds distant; EC. (Fig. 9), N.R., rate about 70; left axis deviation; S-T depression in lead I, T IV diphasic; in leads I and II the beats appear to originate in the A-V node, except for the last two beats in lead I and the last beat in lead II; in the " nodal " beats QRS is wide, S-T depressed, and T negative or diphasic, the pattern being similar to that seen in Case 9 ; in the last cycle but one in lead II QRS is preceded by a $P$ wave with a P-R interval of $0.11 \mathrm{sec}$; this QRS is intermediate in shape between the preceding " nodal" 


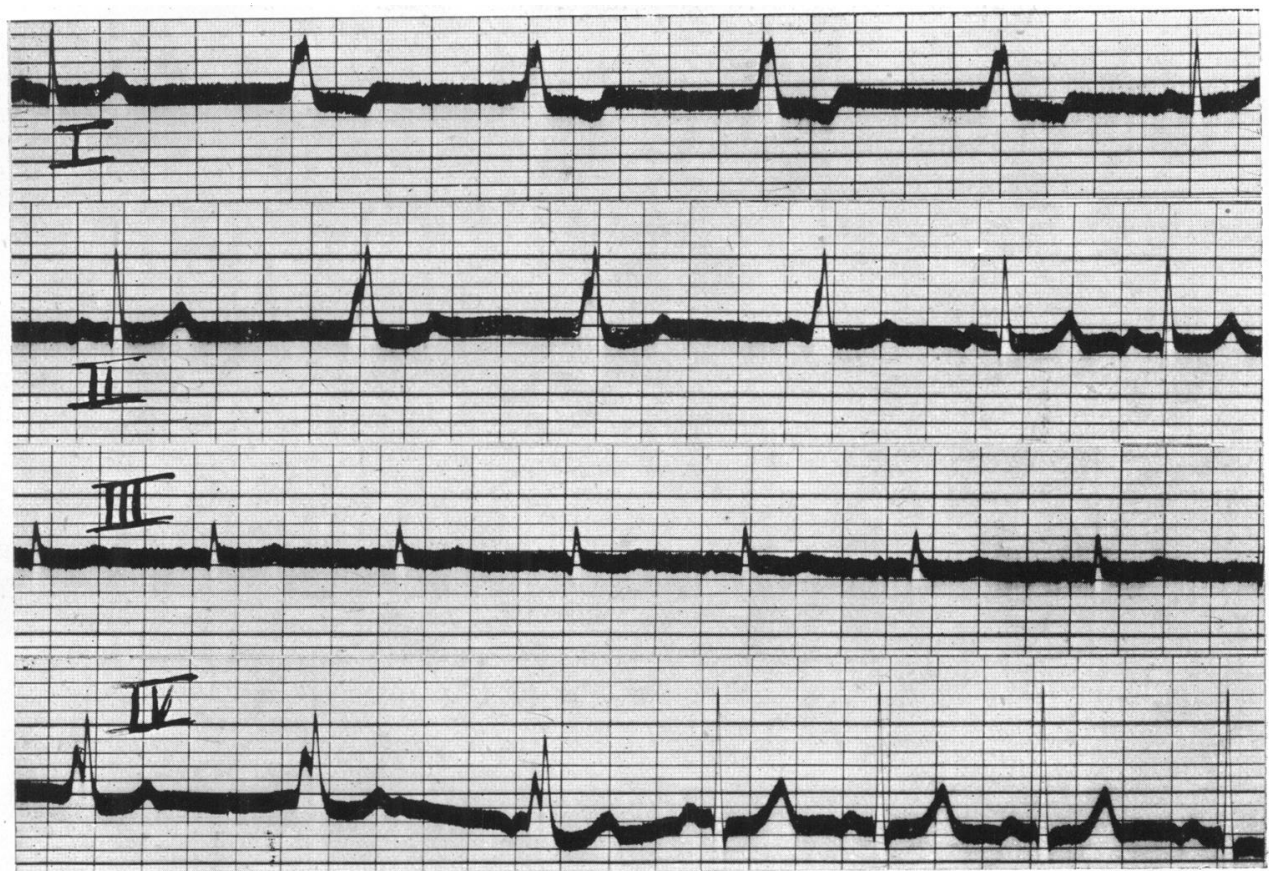

Fig. 8.-Case 9. Nodal escape beats simulating bundle branch block. See text.

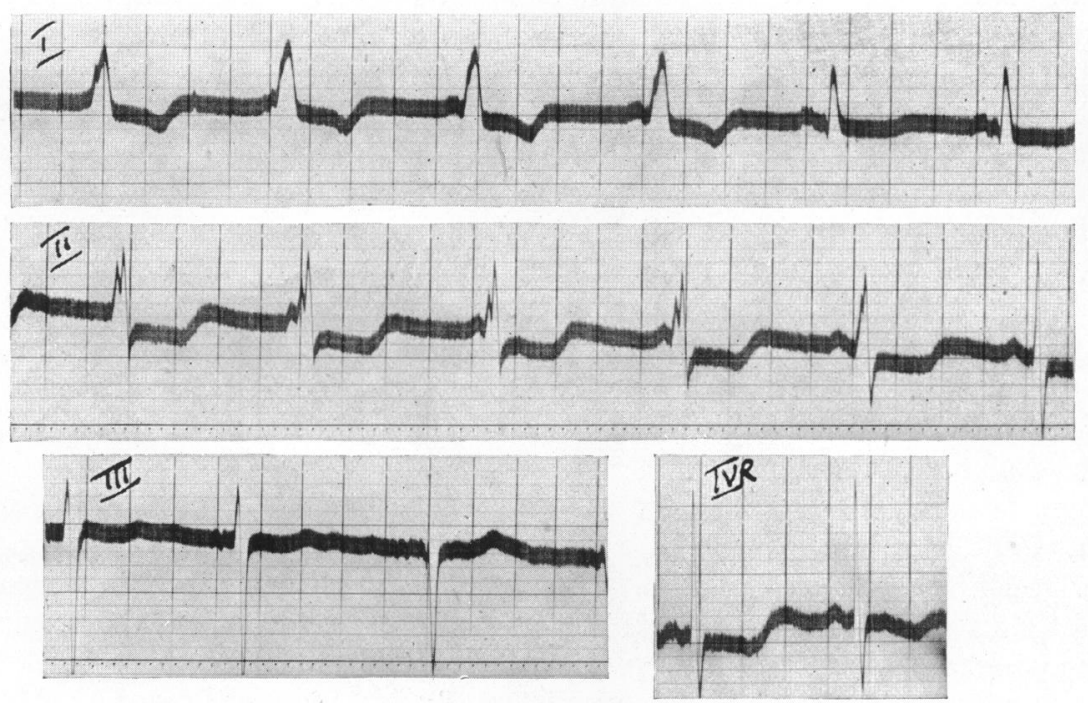

FIG. 9.-Case 10. 9th day. Nodal beats simulating bundle branch block. See text.

and succeeding sinus beat. 22nd day, palatal palsy and heavy albuminuria. 41st day: knee jerks absent, no abnormal cardiac signs; EC., N.R., rate 80, sinus arrhythmia; P-R, 0.12 sec.; T low voltage, and just negative in lead III. 53rd day, facial paralysis. 57th day: EC. N.R., rate 75; left axis deviation; $T$ low voltage and just negative in lead III. Discharged from hospital on 124th day. On re-examination 7 months later, the child was quite well; no abnormal clinical or radioscopic signs; EC., normal rhythm, rate 70; left axis deviation, but QRS and T now of normal amplitude; and T III had become positive.

\section{Discussion}

The histological studies in the four fatal cases show how intense are the degenerative changes in the myocardium in diphtheria and explain the variety of cardiographic changes recorded in the course of the disease. 
Heart Block. An increase in conduction time between auricle and ventricle is not, as in rheumatic carditis one of the commonest manifestations of the myocardial injury, yet some interference with conduction was seen in all the cases with bundle branch or complete block (Cases 5-8) and there were in addition four cases in which an alteration in the P-R interval was the only indication of impaired conductivity .It is in the sub-acute phase of the disease, say after the eighth day, that a large proportion of cases show evidence of cardiac lesions and o systemic congestion, notably by an enlarged tender liver. At this time the heart rate is characteristically not increased and is often slow for a child; this relatively slow rate may conceal a defect in the conducting bundle which might be revealed at higher rates. The sinus bradycardia is another reason, in addition to the occurrence of high ventricular rates in complete block, why cardiography is essential for the diagnosis of block in diphtheria.

The single example of complete block in this series (Case 8) was found in an un-immunized girl aged 8, who had 36,000 of antitoxin intravenously and 40,000 units intramuscularly about 48 hours after the onset of symptoms. From the time of admission there was a progressive deterioration in the clinical condition, cardiograms showing S-T depression in all leads on the fourth day, increase in A-V conduction time and bundle branch block by the sixth day, and by the eighth day when she was vomiting blood and petechiæ were present in the skin, complete block with a ventricular rate of 115 was recorded. Before death on the tenth day the pulse had become slower and irregular due to complete block and alternate ventricular extrasystoles.

Bundle Branch Block. The records of this rhythm (Fig. 2-9), show that the pattern is not fixed but that rapid changes occur from day to day. A frank right bundle branch block picture was commoner than left, but low voltage, concordant, and " $S$ " types and intermittent block were also seen. These quick changes suggest a rapidly extending lesion in the myocardium. But in Case 7 another factor behind these changes is seen, where the QRST pattern altered with the onset of nodal rhythm, both when this appeared spontaneously (Fig. 5), and when induced by an injection of atropine (Fig. 6B). This change may be compared with those to be discussed in connection with Cases 9 and 10. The usual discordant QRST pattern of bundle branch block shows reciprocal deviation of the S-T segment in leads I and III, but in most of the examples recorded here the S-T depression which is a characteristic and early change in toxic diphtheria is superimposed, resulting in S-T depression in all leads. A record from Case 6 taken in the terminal stage (Fig. 3c) does show reciprocal deviation of the S-T segment and is similar to that seen in acute cardiac infarction of posterior type. Studies of sections from this heart showed the most widespread degeneration to be in the posterior wall of the left ventricle with areas of almost complete necrosis.

Auricular Fibrillation and Auricular Flutter. Neither of these rhythms was encountered in any of the patients of this series.

Permanent Lesions. To establish the existence of permanent conducting lesions due to diphtheria it would seem necessary to have records showing the inception of the lesion during the disease. Such records are not always presented in published cases, but even so their number is few and it is generally accepted that however severe the lesions they clear up completely if the patient survives, and that to this rule exceptions are extremely rare. So far as branch block and complete block are concerned, no further light is thrown on this point by the cases reported here as all were fatal. But in one instance of latent block (Case 4) a prolonged $\mathrm{P}-\mathrm{R}$ has persisted for five months, though the complication of chronic rheumatic carditis has to be taken into account. Moreover, persistence for five months is probably insufficient to classify a lesion as permanent.

Simulation of Bundle Branch Block. Two records were obtained (Cases 9 and 10, Fig. 8 and 9), showing abnormal ventricular complexes in beats arising in an ectopic focus, which at first sight suggest bundle branch block. In Case 10 they were discovered on the ninth day when the child was still seriously ill, but in the other on the thirtieth day when the patient was convalescent after a mild attack of the disease. In both instances QRS is wide enough to suggest bundle branch block, but the main deflections are upright and the increase in QRS is mainly due to prolongation of the proximal limb of $R$, the distal limb being little affected. Nor is the direction of T uniformly opposite to that of QRS. Apart from these considerations there is no reason, theoretically, why the function of a bundle branch should 
be impaired during a short period of an ectopic rhythm, while it can conduct impulses from the sinus at a faster rate. In both tracings (Fig. 8 and 9) lead II shows a ventricular complex intermediate between that of nodal and sinus beats when it is preceded by a $\mathbf{P}$ wave, with a $\mathrm{P}-\mathrm{R}$ interval of $0.11 \mathrm{sec}$. The $\mathrm{R}-\mathrm{T}$ interval is increased by up to $0.03 \mathrm{sec}$, , but not more.

These appearances have some similarity to the short P-R, wide QRS pattern, which has been described in particular by Wolff, Parkinson, and White (1930) and by Hunter, Papp, and Parkinson (1940), except that there is no constant relation between the $P$ wave and the ventricular complex and that a passive ectopic rhythm is obviously involved. Many theories have been advanced to explain these complexes, but in the present instances a centre near the A-V node with rhythmicity greater than that of the node itself and from which impulses reach the ventricles by an unusual pathway seems most acceptable. An abnormal conducting path seems indicated by the occurrence of complexes of intermediate form when preceded at sufficient interval by a $\mathrm{P}$ wave. These presumably represent a fusion beat the result of two impulses one from the ectopic focus the other from the sinus, conducted along their own separate routes. Whatever view is accepted, however, the important point is that complexes of this type should not be held to represent a myocardial defect.

\section{SUMMARY}

Clinical and cardiographic findings are given of 8 cases showing conduction changes among a series of 83 patients with diphtheria. Of 4 with latent block, a prolonged $\mathrm{P}-\mathrm{R}$ interval has persisted in one for five months. Bundle branch block in 4 un-immunized children, aged 12 or less, and all died; and complete block was recorded in one of these four. In 2 others bizarre ventricular complexes were found in association with a passive ectopic rhythm; at first sight these suggest a bundle branch lesion: but like the short P-R, wide QRS syndrome, which seems a related condition, these changes do not appear to have any prognostic significance.

I have to thank William McNaughtan for his kind help with the histology; and George Chesney and Gordon Smith, Medical Officers of Health, for kindly allowing me to investigate patients in infectious diseases hospitals.

\section{REFERENCES}

Alstead, S. (1932). Quart. J. Med., 1, 277.

Begg, N. D. (1937). Lancet, 1, 857.

Burkhardt, E. A., Eggleston, C., and Smith, L. W. (1938), Amer. J. med. Sci., 195, 301.

Friedemann, U. (1932). Dtsch. med. Wschr., 43, 1683.

Harries, E. H. R., and Mitman, M. (1941). Clinical Practice in Infectious Diseases. Edin.

Hunter, H., Papp, C., and Parkinson, J. (1940). Brit. Heart J., 2, 107.

Nathanson, M. H. (1928). Arch. intern. Med., 42, 23.

Neubauer, C. (1942). Brit. med. J., 2, 91

Stecher, R. M. (1929). Amer. Heart J., 4, 545.

Wolff, L., Parkinson, J., and White, P. D. (1930). Ibid., 5, 685. 